\title{
$X$. On the discharge of negative ions by glowing metallic oxides, and allied phenomena
}

\section{A. Wehnelt}

To cite this article: A. Wehnelt (1905) X. On the discharge of negative ions by glowing metallic oxides, and allied phenomena, Philosophical Magazine Series 6, 10:55, 80-90, DOI: 10.1080/14786440509463347

To link to this article: http://dx.doi.org/10.1080/14786440509463347

曲 Published online: 16 Apr 2009.

Submit your article to this journal $\pi$

Џ Article views: 9

Q View related articles $\square$

Citing articles: 7 View citing articles 5 
opposite amount for the reverse direction; or, if we set for a match in the one system, the other system would show a change in phase of $0.3 \times 10^{-4} \lambda \div 2$, which is seven times the required effect $10^{-4}$, the aberration constant. With condensers larger than needed for the optical condition, 50,000,000 oscillations have been obtained. Thus

$$
d=\frac{1}{2} \mathrm{~L}=\frac{3 \times 10^{8} \mathrm{M}}{2 \times 0.5 \times 10^{8}}=3 \mathrm{M}
$$

a distance small enough to allow a rotating mount for the system. Higher frequencies are undoubtedly possible; so that, if the above optical sensibility is not attainable, we can still use a rotating support, with a raduction in this factor of, say, ten times. This method thus contains the requisite conditions, if all the experimental difficulties in connexion with the uniformity of the oscillation and the source of light can be overcome. Tho present stage of the work seems to warrant this conclusion.

Physical Laboratory,

University of Nebraska, Lincoln. April 26, 1905 .

X. On the Discharge of Negative Ions* by Glowing Metallic Oxides, and Allied Phenomena. By A. Wennetr †.

$\mathrm{I}^{\mathrm{N}}$ $\mathrm{N}$ a recently published paper $\ddagger$ Mr. Owen has investigated the emission of negative ions by glowing Nernst burners both at atmospheric pressure and in vacuo. As some time previously to the publication of Mr. Owen's paper I had, in two articles, investigated the discharge of negative electricity by metallic oxides, among which were the oxides composing Nernst burners, perhaps I may be permitted to present here a short account of my experimental results. For details and fuller bibliographical references, the reader is referred to the original articles.

\section{Emission of Negative Ions by Glowing Metallie Oxides at Atmospheric Pressure.}

The metallic oxides to be investigated were in each case supported by carefully cleaned platinum wires of the same length and thickness, which were in turn fixed along the axis of a hollow brass eylinder. The wire and cylinder were enclosed in a glass tube to prevent convection currents of air.

* Negative ion $=$ electron $=$ corpuscle.

$\dagger$ Communicated by the Author. Cf. A. Wehnelt, Sitzungsber..der physik.-medicinischen Soc. Erlangen, pp. 150-158 (1903); Ann. der Physik, xiv. pp. 425-468 (1904); Verhandl. d. Deutsch. physik. Gesellsch. v. pp. $255-258 \&$ pp. $423-426(1903)$.

$\neq$ G. Owen, Phil. Mag. viii. pp. 230-257 (1904). 
The platinum wire was heated by an alternating current from a small transformer having a well-insulated secondary, and could be raised to anv desired potential by connecting it to one pole of a high-voltage battery, whose other pole was earthed. The cylinder was connected to earth through a galvanometer.

In the case of a pure platinum wire, as well as in that of one covered with oxide, no well-marked saturation currents are reached at atmospheric pressure. Hence the current was in every instance measured at the same constant potential difference of 1000 volts.

The oxides of the following metals were investigated :-

(1) Barium, stroniium, calcium, magnesium, zinc, cadmium, yttrium, lanthanum, zirconium, thorium.

(2) Beryllium, aluminium, thallium, titanium, cerium, iron, nickel, cobalt, chromium, uranium, tin, lead, bismuth, silver, copper.

Oxides belonging to group (2) showed an emission of corpuscles which was either not at all or else only very slightly higher than that of pure platinum, while oxides of the first group showed a considerably stronger discharge of negative electricity. The oxides of calcium, barium, and strontium exhibited an abnormally powerful discharge, and this led me to select these oxides for a more detailed quantitative examination.

Table I. contains the currents which flowed through the

TabLe I.

Relation connecting current ( $i$, in $10^{-8}$ amp.) with temperature (T), at atmospheric pressure.

\begin{tabular}{|c|c|c|c|c|}
\hline \multirow{2}{*}{ T. } & \multicolumn{2}{|c|}{ Pure Platinum Wire. } & \multicolumn{2}{|c|}{ Wire coated with $\mathrm{BaO}$. } \\
\hline & $+i$ & $-i$ & $+i$ & $-i$ \\
\hline $\begin{array}{l}880 \\
070\end{array}$ & 0.95 & 0.95 & & \\
\hline $\begin{array}{r}800 \\
1050\end{array}$ & $\dddot{1} \cdot 14$ & 0.95 & $\begin{array}{l}0.95 \\
1 \cdot 14\end{array}$ & 23.7 \\
\hline 1070 & & & & 507 \\
\hline 1090 & $\cdots$ & $\cdots$ & $\ldots$ & $87 \cdot 5$ \\
\hline 1105 & 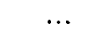 & . & 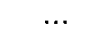 & 200 \\
\hline 1120 & $\ldots$ & $\ldots$ & $\ldots$ & 400 \\
\hline 1140 & & & & 780 \\
\hline 1220 & 1.95 & $\begin{array}{l}0.95 \\
0.95\end{array}$ & 1.52 & \\
\hline $\begin{array}{l}1300 \\
1380\end{array}$ & 10.1 & $2 \cdot 28$ & $\begin{array}{l}2 \cdot 85 \\
8 \cdot 56\end{array}$ & \\
\hline 1460 & $26 \cdot 6$ & $27 \cdot 6$ & $43 \cdot 7$ & \\
\hline
\end{tabular}

$[+i$ and $-i$ indicate, respectively, positive and negative potential of the glowing wire.]

Phil. Mag. S. 6. Vol. 10. No. 55. July 1905. 
galvanometer at various temperatures of the pure or bariumoxide-coated wire when maintained at a potential of \pm 1000 volts.

These results are exhibited in the curves of fig. 1 . The Fig. 1.

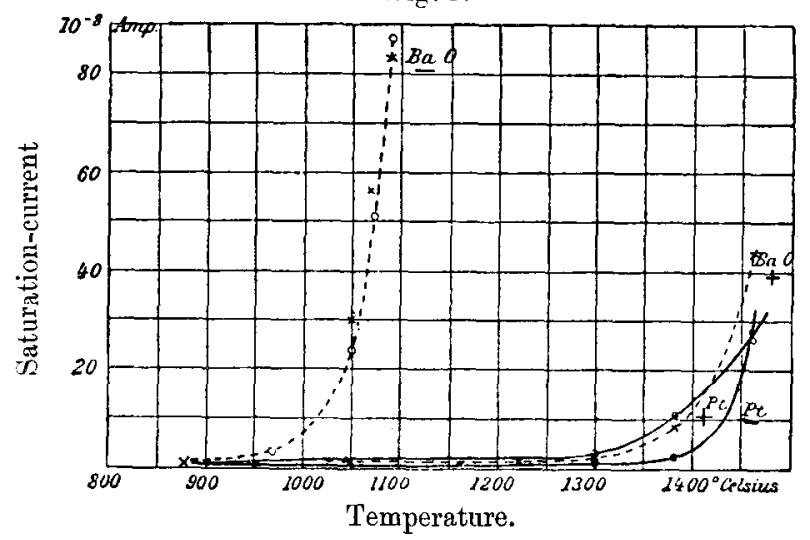

full-line curves show the connexion between $i$ and T for pure platinum wire. From them it will be seen that for temperatures below $1450^{\circ}$ there are sent out more positive than negative ions*, while at higher temperatures the reverse appears to take place.

Much more marked than this slight difference between the numbers of the positive and negative ions in the case of pure platinum is that which occurs when the wire is coated with barium oxide (dotted curves of fig. 1). While the currents corresponding to a positive potential do not appreciably differ from those obtained with a pure platinum wire, the currents with the wire at a negative potential are extraordinarily large even at low temperatures.

Similar results, both qualitatively and quantitatively, were obtained with the oxides of calcium and barium.

\section{Emission of Negative Ions by Glowing Metallic Oxides at Low Pressures.}

According to the united testimony of all investigators $\dagger$, a platinum wire heated in vacuo emits principally negative ions.

* This result is in accordance with those obtained by other workers. Detailes bibliographical references will be found in J. J. Thomson's 'Conduction of Electricity through Gases,' Chapter viii. (1903).

$\dagger$ J. Elster and H. Geitel, Wied. Ann. xxxvii. p. 315 (1889). J. J. Thomson, Phil. Mag. xlviii. p. 547 (1899). O. W. Richardson, Proc. Cambr. Phil. Soc. xi. pp. 286-295 (1901); Phil. 'Srans. cci. p. 516 (1903). McClelland, Proc. Cambr. Phil. Soc. xi. p. 296 (1991). H. A. Wilson, Proc. Roy. Soc. lxxii. pp. 242-276 (1.903), and Phii. Trans. ccii. p. 252 (1903). 
The number of corpuscles emitted by glowing platinum was investigated in detail by Messrs. 0 . W. Richardson* and H. A. Wilson $\dagger$, according to whom-as had already been found by J. J. Thomson-the relation between the number of negative ions and the absolute temperature may be represented by an exponential formula, into which the number of corpuscles contained in unit volume enters as a constant. This number, according to Richardson's researches, amounts in the case of platinum to about $10^{21}$.

Now I have investigated the emission of negative ions by platinum wires coated with the oxides of calcium, barium, and strontium, and found that, for equal temperatures, the oxide-coated wires emit far more corpuseles than the pure platinum wires.

The experimental arrangements were essentially the same as in the previous investigations, only in this case various leading wires to the electrodes were melted into the glass, and the tube was fused on to a mercury pump having no greased joints $\ddagger$.

At pressures less than $0 \cdot 1 \mathrm{~mm}$. of mercury, well-marked saturation-currents were observed which were independent of the pressure. At pressures exceeding $0.1 \mathrm{~mm}$., ionization already occurred by ionic impact, the saturation currents were not well marked, and were in addition dependent on the pressure. Hence, in order to find the relation connecting the saturation current with temperature, pressures less than $0.1 \mathrm{~mm}$. were invariably used.

In what follows, the results will be given for $\mathrm{BaO}$ alone, as those obtained with $\mathrm{CaO}$ and $\mathrm{SrO}$ were very similar, both qualitatively and quantitatively. The results cannot, of course, be expected to be perfectly concordant, as a perfectly uniform coating of the wires with the oxides is unattainable.

Table II. contains the results obtained with $\mathrm{BaO}$; instead of the saturation-current, the saturation current-densities are given-i.e., the currents per nnit of area $\left[i \mathrm{~cm}^{-2}\right]$.

Table II.-Relation connecting Saturation Current-Density $\left(i \mathrm{~cm} .{ }^{-2}\right.$ ) with Temperature (I). Wire coated with $\mathrm{BaO}$. $p=0.04 \mathrm{~mm}$. of mercury.

\begin{tabular}{|c|c|c|c|c|c|c|c|}
\hline $\mathrm{T}$ & $960^{\circ}$. & $1050^{\circ}$ & $1140^{\circ}$. & $1220^{\circ}$. & $1300^{\circ}$. & $1380^{\circ}$ & $1460^{\circ}$. \\
\hline$i \mathrm{~cm}-2$ & $\overline{3} .10^{-7}$ & $3 \cdot 8 \cdot 10-6 \mid$ & $3 \cdot 14.10-5$ & $2 \cdot 18.10^{-4}$ & $|1 \cdot 6.10-3|$ & $8 \cdot 1.10-3$ & $24.10-2$ \\
\hline
\end{tabular}

* Loc. cit.

$\dagger$ Loc. cit.

I Sealing-wax joints and joints rendered air-tight by means of grease were avoided, as the vapours of organic compounds are decomposed by the glowing wire, whereby the caating of oxide on the wire is destroyed. The carbides formed canse a black deposit on the walls of the glass tube. 
These results are graphically exhibited in fig. 2.

Fig. 2.

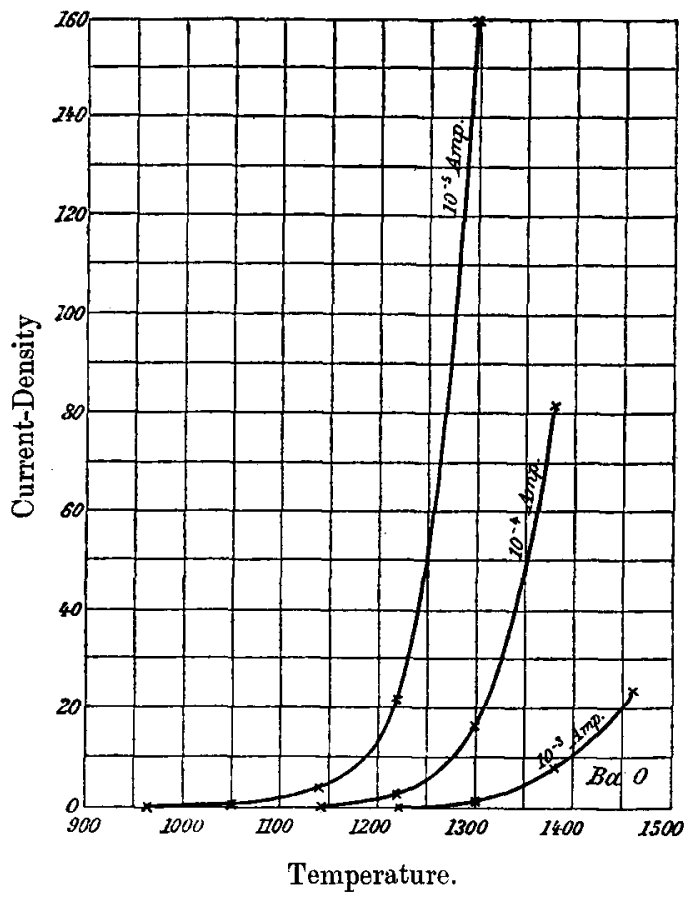

On comparing these curves with those obtained by Mr. 0 . W. Richardson* for pure platinum, it is found that they possess precisely the same character. An application of the test suggested by Mr. O.W. Richardson to my results showed that his exponential formula satisfactorily represents the connexion between the number of corpuscles emitted and the temperature in the case of metallic oxides also.

From the much stronger emission of negative ions by the oxides, I concluded that the latter contain more corpuscles per unit of volume than platinum. A calculation of the number contained in unit volume leads, on the other handas has recently been shown by Mr. O. W. Richardson †-to

* O. W. Richardson, Proc. Cambr. Phil. Sac. xi. p. 291 (1901).

$\dagger$ O. W. Richardson, Jahrbuch für Radroaktivität und Elektronik, i. p. $313(1904)$. 
the same value as that for platinum. From this Mr. Richardson concludes that the corpuscles proceed not from the glowing oxide, but from the platinum, and that the action of the oxides is confined to a reduction of the amount of energy required to liberate the corpuscles. Experiments to settle this point are in progress at this Institute.

\section{Glowing Metallic Oxides as Cathodes in Discharge Tubes.}

According to our modern views, the cathode dark space of a glow discharge represents a region poor in negative ions*. If this impoverishment is prevented by introducing into the dark space corpuseles produced by any convenient method, their presence results-as has been shown experimentally by Herr G. C. Schmidt-in a lowering of the potential drop at the cathode.

Now glowing metallic oxides emit, as we have seen, numerous negative ions. Hence, when used as cathodes they should produce a lowering of the cathode drop which increases with increasing temperature.

Experiments on this point confirmed the truth of this conclusion.

In what follows are given the results of quantitative experiments made to determine the connexion between the eathode drop on the one hand, and the current, pressure, and temperature of the metallic oxide cathode on the other.

The spherical discharge-tube used in the experiments had for cathode a platinum wire coated with the oxide under investigation, the wire being heated by an alternating current. The temperature was measured by means of a very thin platinum-platinum-rhodium thermocouple. An exploring electrode near the cathode enabled the cathode drop to be measured. A wire of aluminium served as anode.

Connexion between Cathode Drop and Current.-In the first place, I investigated the dependence of the cathode drop on the current at various temperatures of the cathode. The results for the oxides of barium, calcium, and strontium are almost identical, qualitatively as well as quantitatively, so that I here give, in Table III., only the values obtained with $\mathrm{CaO}$.

* J. J. Thomson, Phil. Mag. xlvii. p. 253 (1899). J. Stark, Ann. d. Physik, ii. p. 62 (1900). G. C. Schmidt, Ann.d. Physik, xii. p. 622 (1903). A. Wehnelt, Ann. d. Physik, x. p. 569 (1903). 


\section{TABLe III.}

Relation connecting Cathode Drop $(\mathrm{K})$ with Current (i) at a glowing CaO-Cathode, at Constant Temperature (T) and Constant Pressure $(p)$.

\begin{tabular}{|c|c|c|c|c|c|c|c|c|c|}
\hline$p=0.83 \mathrm{~mm} . \mathbf{\mathrm { mg }} .752^{\circ}$. & $\begin{array}{l}i, 10-3 \text { amp. } \\
\mathbf{K} \text { in volts. }\end{array}$ & $\begin{array}{l}0.026 \\
1.2\end{array}$ & $\begin{array}{l}0.053 \\
3.2\end{array}$ & $\begin{array}{l}0.057 \\
6.5\end{array}$ & $\begin{array}{r}0.1 \\
33 \cdot 7\end{array}$ & 61 & & & \\
\hline $\begin{array}{r}\mathrm{T}=820^{\circ} \\
p=0.84 \mathrm{mw} . \mathrm{Hg}_{\mathrm{g}},\end{array}$ & $\begin{array}{l}i, 10-3 \text { amp. } \\
\mathbf{K} \text { in volts. }\end{array}$ & $\begin{array}{l}0.035 \\
0.9\end{array}$ & $\begin{array}{l}0 \cdot 14 \\
1 \cdot 36\end{array}$ & $\begin{array}{l}0 \cdot 2 \\
2 \cdot 9\end{array}$ & $\begin{array}{l}0.28 \\
10 \cdot 2\end{array}$ & $28 \cdot 4$ & $\begin{array}{c}0 \cdot 54 \\
43 \cdot 2\end{array}$ & $\begin{array}{c}0 \cdot 68 \\
54 \cdot 8\end{array}$ & $\begin{array}{c}1 \\
76 \cdot 2\end{array}$ \\
\hline $\begin{array}{r}\mathrm{T}=895^{\circ} \\
p=0.84 \mathrm{~mm} . \mathrm{Hg} .\end{array}$ & $\begin{array}{l}i, 10-3 \text { amp. } \\
\bar{\kappa} \text { in volts. }\end{array}$ & $\begin{array}{l}0.025 \\
1 \cdot 14\end{array}$ & $\begin{array}{l}0 \cdot 11 \\
1.53\end{array}$ & $\begin{array}{l}0.27 \\
1.53\end{array}$ & $\begin{array}{l}0 \cdot 41 \\
2 \cdot 2 \cdot 2\end{array}$ & $\begin{array}{l}0.48 \\
295\end{array}$ & $\begin{array}{l}0 \cdot 55 \\
3 \cdot 24\end{array}$ & $\begin{array}{c}0 \cdot 68 \\
15 \cdot 8\end{array}$ & $\begin{array}{c}1 \\
307\end{array}$ \\
\hline $\begin{array}{r}\mathrm{T}=984^{\circ} \\
p=0.87 \mathrm{~mm} . \mathrm{Hg} .\end{array}$ & $\begin{array}{l}i, 10-3 \text { amp. } \\
\mathbf{K} \text { in rolts. }\end{array}$ & $\begin{array}{l}0.028 \\
1 \cdot 2\end{array}$ & $\begin{array}{l}0 \cdot 14 \\
1 \cdot 5\end{array}$ & $\begin{array}{l}0.28 \\
1 \cdot 6\end{array}$ & $\begin{array}{l}0.41 \\
1.7\end{array}$ & $\begin{array}{l}0.55 \\
1.8\end{array}$ & $\begin{array}{l}0.75 \\
1.9\end{array}$ & $\begin{array}{l}1 \\
2\end{array}$ & $22^{2} \cdot 3$ \\
\hline
\end{tabular}

Fig. 3 exhibits these results graphically. The curves show Fig. 3.

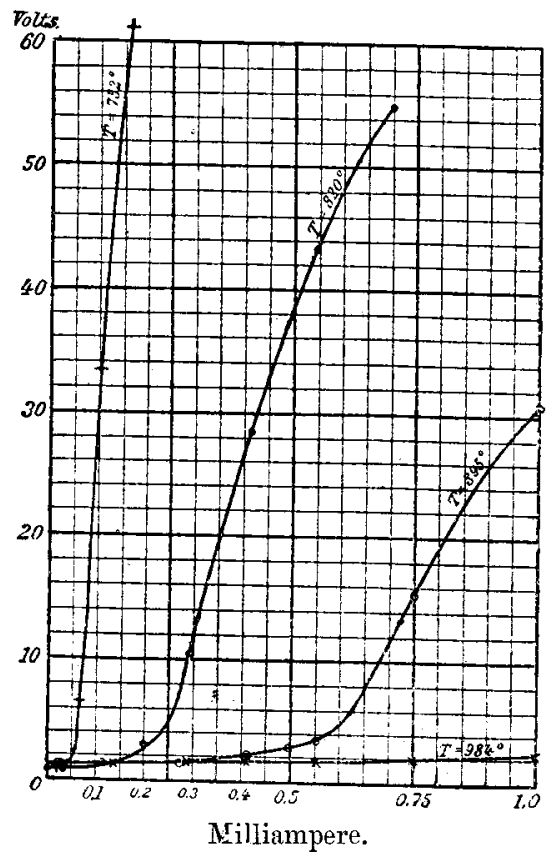

that up to a certain value of the current, characteristic of each temperature and increasing with rise of temperature, the cathode drop is nearly constant and very small [the small residual potential difference of from 1 to 2 volts between the 
exploring electrode and the cathode is, no doubt, due to the fall along the positive column], but that it rapidly increases at soon as the characieristic current is exceeded. This current I have named the limiting current.

Since the limiting current increases with rise of temperature I have investigated the relation connecting the two quantities somewhat more closely.

Connexion between Limiting Current and Temperature.By slowly increasing the current at various temperatures, that value of it was determined beyond which the cathode drop just commenced to increase-i. e., the limiting value of the current. The relations so obtained between the limiting curreut and temperature are nearly identical, qualitatively as well as quantitativeiy, for the oxides of calcium, barium, and strontium ; bence, in this case also, I give, in Table IV, the results obtained with $\mathrm{CaO}$ only.

\section{Table IV.}

Relation connecting Limiting Current with Temperature ( $\mathrm{CaO}$ cathode). $\quad p=$ about $0.01 \mathrm{~mm}$. $\mathrm{Hg}$.

\begin{tabular}{|c|c|c|c|c|c|c|c|c|c|}
\hline Temperature & 945 & 1012 & 1075 & 1133 & 1192 & 1252 & 1313 & 1367 & $1485^{\circ}$ \\
\hline Limiting Current, $10-3 \mathrm{amp}$. & $0 \cdot 1$ & 0.56 & $1 \cdot 68$ & $5 \cdot 6$ & $11 \cdot 8$ & $26^{*}$ & $35 \cdot 4^{*}$ & $56 \cdot 1 *$ & $700^{*}$ \\
\hline $\left.\begin{array}{l}\text { Limiting Current - density, } \\
\text { in } 10^{-3} \text { amp. cm. }-2 \text {...... }\end{array}\right\}$ & 0.24 & $1 \cdot 2$ & 3.57 & 12 & 25 & 55 & 75 & 120 & 1500 \\
\hline
\end{tabular}

In the third row of the table are given the limiting currentdensities, $i . e$. , the limiting currents per unit of area $\left[i \mathrm{~cm} .^{-2}\right]$ of the glowing oxide. As will be seen, the current-density reaches a very large value at high temperatures.

The curves drawn in fig. 4 have been plotted from Table IV. With increasing pressure the limiting current decreases, but otherwise the relation connecting limiting current with temperature remains unaltered $\dagger$.

Meaning of Limiting Current.-As already mentioned above, according to modern views the cathode dark space represents a region pcor in negative ions. If into it we introduce corpuscles generated by any suitable method, the cathode drop will decrease. If now we increase the current through the discharge-tube, we do away with more negative ions, the

* With large currents, the walls of the tube became strongly heated, so that the pressure could no longer be kept constant, but increased almost to $1 \mathrm{~mm}$.

$\dagger$ A. Wehnelt, Ann. d. Physik, xiv. p. 451 (1904). 
impoverishment as regards such ions again increases, and hence the cathode drop will increase.

Fig. 4.

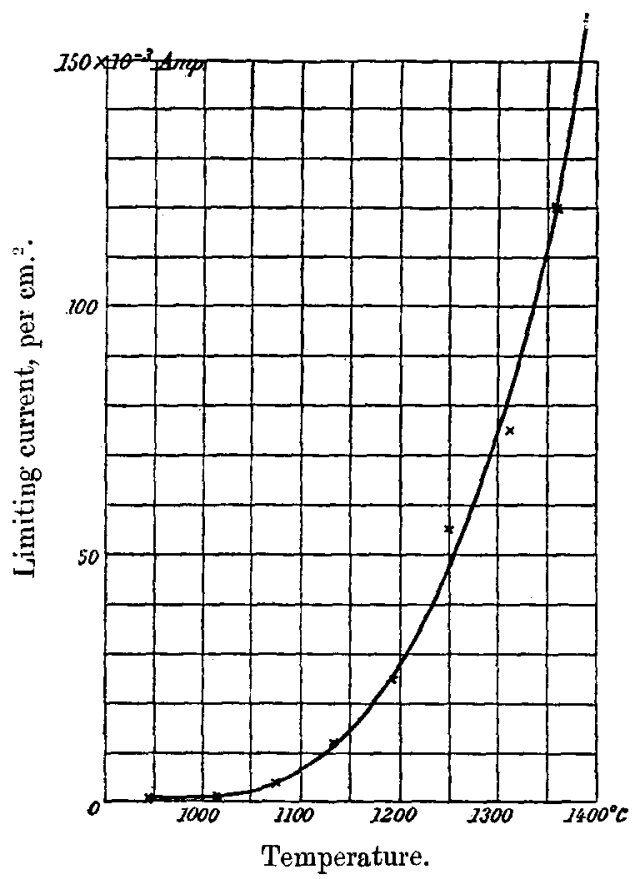

Now the glowing oxides emit, as we have seen, numerous corpuscles. If the number emitted exceeds the number absorbed by the passage of the current, there will be no impoverishment, $i$. e., the cathode drop will be zero. As the current through the tube is increased, it finally reaches a value such that the number of ions absorbed per unit of time by the current becomes exactly equal to the number furnished by the glowing oxide during the same interval. Up to this value of the current, no impoverishment as regards negative ions takes place, so that the cathode drop is zero. If now the current through the tube be further increased, more corpuscles will be absorbed than are generated, and the cathode drop will begin to rise.

Hence the current which I have defined as the limiting current is that for which the ahsorption of negative ions and the impoverishment thereby brought about just ceases to be compensated by the corpuscles emitted by the glowing oxides. 
If this view is correct, then the limiting current must increase in proportion to the number of ions emitted by the oxide. But the number of corpuscles emitted by the oxide is directly proportional to the measured saturation current, so that the limiting current should increase in direct proportion to the saturation current. An examination of the experimental results from this point of view showed the correctness of this conclusion.

\section{Applications of Glowing Metallic Oxide Cathodes in the Construction of Discharge Tuhes*.}

1. When the glowing oxide cathodes are at a very high temperature, the limiting current-density reaches a value of several amperes per unit of area $\left[\mathrm{cm}^{2}\right]$. These high limiting current-densities enable as, by the use of glowing oxide cathodes having areas of several square centimetres, to send much stronger currents through the discharge-tubes than has hitherto been possible. This is due to the fact that with ordinary tubes the catbode drop even with feeble currents already far exceeds the normal value of 300 volts. The conditions are essentially different in the case of the strong currents which may be sent through mercury vapour.

The fall of potential along the positive column is, as has been shown by special measurements, under low pressures and within the range of 0.1 to 15 amperes, entirely independent of the current and lies between 1 and 2 volts per $\mathrm{cm}$. More exact measurements on this point are not yet available, as the heating of the walls of the tube by the strong currents liberates a large amount of gas from them, whereby the pressure and with it the potential gradient along the positive column is greatly increased.

The small drop along the positive column, combined with the absence of a drop at the cathode, renders it possible to work fairly long tubes by means of voltages such as are furnished by electric light circuits [110 to 220 volts]. The regular positive layers which are formed with strong currents glow with extraordinary brightness, and promise to supply a valuable aid in the examination of gas spectra in spectrum analysis. The ultra-violet rays might be allowed to escape through quartz windows cemented into the tube.

2. If in a discharge-tube the anode be brought close up to the glowing oxide cathode, the positive column disappears, and there remains only the anode drop of some 20 volts; i. e., a potential-difference of little over 20 volts is sufficient

* The tubes here described are obtainable from E. Gundelach, Gehlberg, in Thuringia. 
to send a current through the tube. But if the polarity were reversed, so as to make the glowing oxide electrode the anode, and the cold metal electrode the cathode, then at low pressures several thousand volts would be necessary to send a current through the tube. Hence, if such a discharge-tube be introduced into a low-voltage (110 to 220 volt) alternating current circuit, it will act as a valve, allowing only one halfwave of the alternating current to pass through it. The tube may then be used in a manner similar to that of Grätz's aluminium rectifier, for the purpose of charging accumulators, or working induction-coils having electrolytic interrupters, by means of alternating currents.

3 . If the limiting value of the current be exceeded in a discharge-tube with glowing oxide cathode, the catbode drop may be given any desired value, and so the cathode rays any desired velocity.

By the use of a cathode consisting of a narrow bare strip of platinum foil, having only a small circular patch (about $1 \mathrm{~mm} .{ }^{2}$ in area) of $\mathrm{CaO}$ on it, the entire discharge, when the platinum glows, may be made to pass through the $\mathrm{CaO}$ patch, so that from this latter there issues a very thin pencil of cathode rays, having a direction normal to the foil. These rays may be given any desired velocity by a proper choice of the temperature and the current. They are extraordinarily bright, so as to be visible even in a fairly large darkened lecture-room.

If the tube be introduced into a uniform magnetic field whose direction is perpendicular to that of the cathode rays as they leave the cathode, the rays are bent into completely closed circles, whose radius of curvature is easily determined. If in addition to this the total discharge potential-difference be measured by means of a voltmeter, and from it there be subtracted 20 volts to allow for the anode drop, the cathode drop becomes approximately known, and thus it becomes possible to demonstrate to a large audience, in a simple and easily intelligible manner, the determination of the ratio of charge to mass $\left[\frac{\epsilon}{\mu}\right]$ and of the velocity $[v]$ of cathode rays. By varying the cathode drop within wide limits (5 to 200 volts or more) it then further becomes possible to demonstrate that the ratio $\frac{\epsilon}{\mu}$ remains constant within these limits, while $v$, on the other hand, increases with increasing cathode drop.

Erlangen, Physical Institute of the University, April 1905. 